\title{
Study of Eccentric Load Coefficient of Pre-stressed Concrete Partial Cable-Stayed Bridge with Corrugated Steel Webs
}

\author{
Yuze Nian", a, Junliang Tian², b, Suisheng Li², c, Wenjuan $\mathrm{Liu}^{2, \mathrm{~d}}$, Tao Hu${ }^{2, ~ e}$, \\ Canhua Chang ${ }^{2, f}$
}

${ }^{1}$ School of Transportation, Southeast University, Nianjing, 210096, China

${ }^{2}$ Highway Administer Department of Zhengzhou, Zhengzhou, 450015, China

${ }^{2}$ Highway Administer Department of Zhengzhou, Zhengzhou, 450015, China

${ }^{2}$ Highway Administer Department of Zhengzhou, Zhengzhou, 450015, China

${ }^{2}$ Highway Administer Department of Zhengzhou, Zhengzhou, 450015, China

${ }^{2}$ Highway Administer Department of Zhengzhou, Zhengzhou, 450015, China

anianyz1990@163.com, b13666241@qq.com, c1355066319@qq.com, d1412268105@qq.com, esjyht2004@163.com, ${ }^{+33355938 @ q q . c o m ~}$

Keywords: corrugated steel webs; partial cable-stayed bridge; finite element computation; eccentric load coefficient

Abstract: In the variable cross-section continuous box girder bridge, due to the complex internal force influence surface of the load, the effect of the box beam geometry on restrained torsional stresses changes along the span of the bridge. Therefore, unified partial load coefficient should not be used over the whole bridge. Through the theoretical analysis and finite element computation based on a real bridge, this paper explores distribution laws of load coefficient along the spans in the variable cross-section pre-stressed concrete partial cable-stayed bridge with corrugated steel webs and proposes practical load coefficient to offer some recommendations for engineering design.

\section{Introduction}

CB Company firstly proposed the PC composite beam in 1975. After that, the PC composite beam has a wide development in Japan and other countries [1]. However, until now, there are few researches focused on the effect of eccentric load [2-3]. So, the objective of this paper is to make a systematic research with the finite element analysis. By the load equivalent method, the effect of eccentric load $\mathrm{p}$ is divided into the following three variants [4-5] (shown in the dashed box in Figure 1): bending under symmetric load, constrained torsion under torque, distortion under counter force.

The figure 1 shows that, under the eccentric force, the stress at any point on the cross section of the box girder can be divided into three parts: bending stress (symmetric load effect), restrained torsional stress (anti-symmetric load effect), warping and distortion stress (anti-symmetric load effect).

Under the eccentric force, because the empirical estimation method is not applicable to the type of bridge [6-7], the normal stress at a point of the box girder is calculated as the following equation:

$$
\sigma_{z}=\sigma_{b}+\sigma_{t}+\sigma_{d}
$$

The shear stress is calculated as the following equation:

$$
\tau_{z}=\tau_{b}+\tau_{t}+\tau_{d}
$$

Therefore, the eccentric load coefficient of the normal stress is defined as the following:

$$
\xi=\frac{\sigma_{b}+\sigma_{t}+\sigma_{d}}{\sigma_{b}}
$$


The eccentric load coefficient of the normal stress is defined as the following:

$$
\eta=\frac{\tau_{b}+\tau_{t}+\tau_{d}}{\tau_{b}}
$$
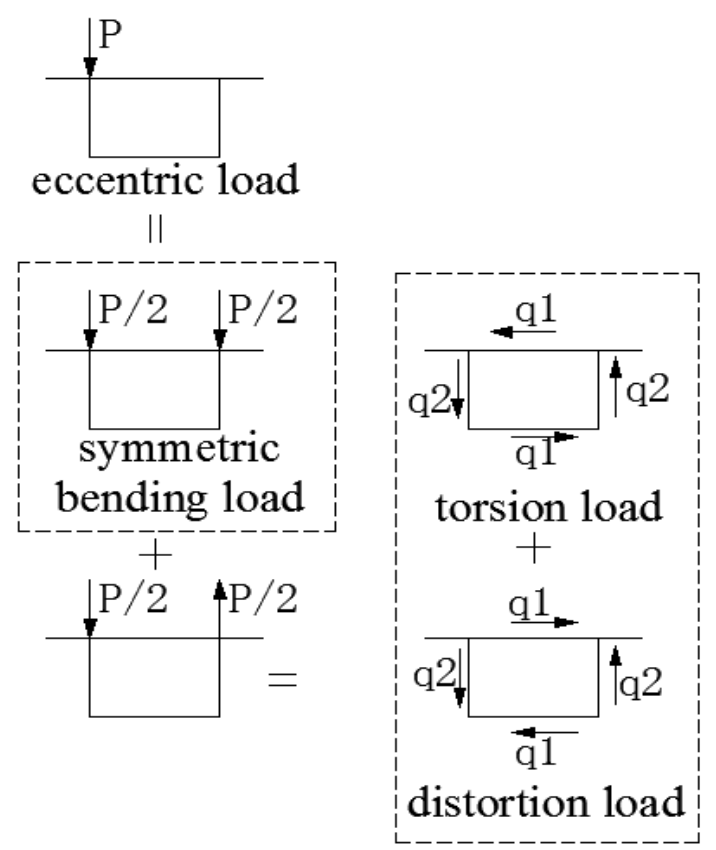

Figure 1 Division of eccentric force $\mathrm{P}$

In these equations, $\sigma_{z}$ is normal stress, ${ }{ }_{z}$ is shear stress, ${ }^{\xi}$ is eccentric load coefficient of the normal stress, $\eta$ is eccentric load coefficient of the normal stress, $\sigma_{b}$ is bending normal stress under the symmetrical load, ${ }^{\sigma_{t}}$ is restrained torsional normal stress under anti-symmetric load, $\sigma_{d}$ is warping and distortion normal stress under anti-symmetric load, ${ }^{b}$ is bending shear stress under the symmetrical load, $\tau_{t}$ is restrained torsional shear stress under anti-symmetric load, $\tau_{d}$ is warping and distortion shear stress under anti-symmetric load.

\section{Project overview}

The uniform appearance will assist the reader to read paper of the proceedings. It is therefore suggested to authors to use the example of this file to construct their papers. This particular example uses an American letter format with $25 \mathrm{~mm}$ margins left, right, top and bottom.

Chaoyang Bridge is $484.8 \mathrm{~m}$ long, consisted of $58+118+188+108=472 \mathrm{~m}$. The superstructure is partial cable-stayed bridge with corrugated steel webs. P2 and P3 piers use double thin-walled solid Pier and are fixed with the main beam and the main tower. P1 pier uses solid thin-walled Pier and the pot bearing is set on the top of it. Number A4 base is bored pile foundation and the others are all spread foundation. The bridge plane is located in round curve with $3900 \mathrm{~m}$ radius. The bridge span is designed by the bridge line. Piers are set in radial direction.

The main box beams are made up of C55 concrete, and the main tower is made up of C50 concrete. Base piles of P2, P3 Pier are made up of C30 concrete. The internal tendon is steel strand with high strength and low relaxation. Its standard value of axial tensile strength is $1860 \mathrm{MPa}$, and the steel strand has the diameter for $15.2 \mathrm{~mm}$, area for 139.0, and elasticity modulus for $1.95 \mathrm{MPa}$. The external tendon is steel strand with epoxy coating, high strength and low relaxation, and the standard value of axial tensile strength is $1860 \mathrm{MPa}$. The thickness of corrugated steel is $12 \sim 24 \mathrm{~mm}$, and the type is 1600. General arrangement of the bridge is shown in Figure 2. 


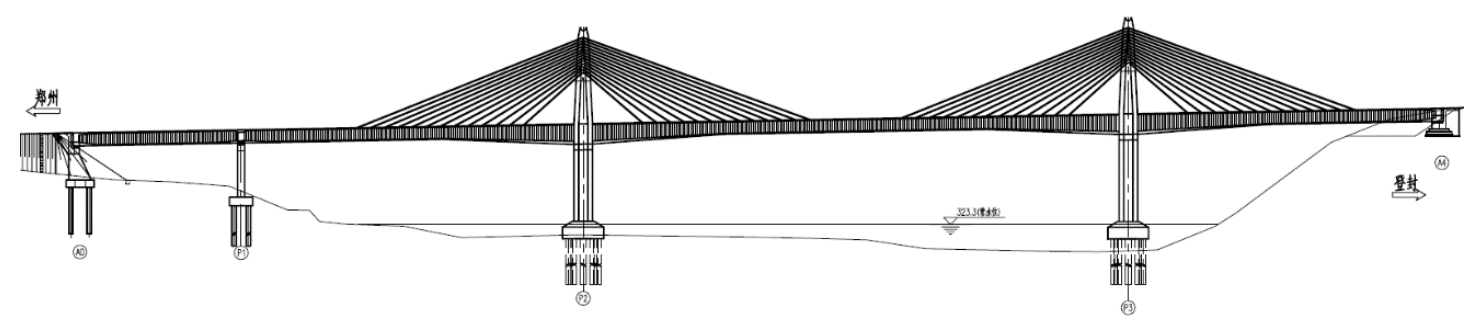

Figure 2 General arrangement

\section{Structure analysis}

This article adopts the finite element software ANSYS15.0 to build the whole bridge model to carry on the numerical simulation, as shown in Figure 3. The concrete and concrete diaphragm plate is simulated by Solid 45 entity unit, corrugated steel web is simulated by the Shell 181 units, cables and pre-stressed steel (including in vivo and in vitro) is simulated by Link8 bar units, and the main joist steel beam is simulated by Beam44 element. The amount of bridge units is 1167684 .

Refer to the purpose of static load test of this bridge and assess regulations of the highway bridge bearing capacity (JTG/T J21-2011), the efficiency coefficient of static test load $\eta_{q}$ has the range:

$$
\begin{aligned}
& 0.95 \leq{ }^{\eta_{q}} \leq 1.05 \\
& \eta_{q}=\frac{S_{s}}{S^{\prime} \cdot(1+\mu)}
\end{aligned}
$$

In the equations, $S_{s}$ is the maximum value of internal force of control sections under the static test load. S' is the value of the most adverse effect of testing load, and for this bridge, the value is calculated under the bridge design load. ${ }^{\mu}$ is the impact coefficient. $\eta_{q}$ is the efficiency coefficient of static test load.

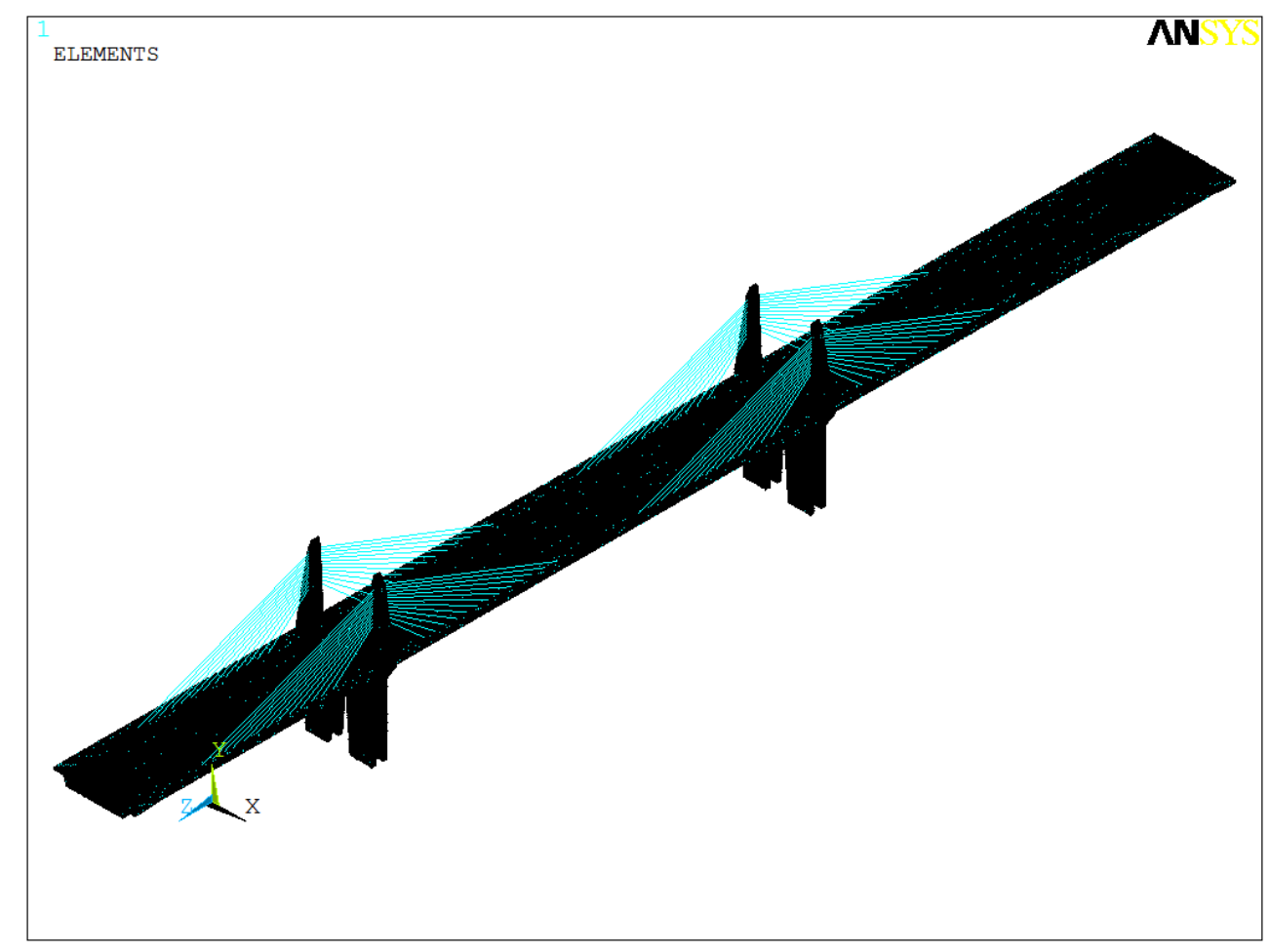

Figure 3 Whole bridge model

Test load is determined by bending moment of control section under serviceability limit state loads. Use the maximum value of design live load as the control value of test load. Impact factor is 
calculated by the standard. Fundamental frequency is calculated by the FEM. The influence lines of internal force of cross sections are shown in Figure 4, in which (a), (b), (c), (d) is namely the internal force influence lines of $58 \mathrm{~m}, 118 \mathrm{~m}, 188 \mathrm{~m}$ and $108 \mathrm{~m}$ cross sections.

As shown in Figure 5, along the longitudinal direction, there are 15 main control sections Z1 Z15. And the arrangement of monitoring stations on each key section is shown in Figure 6. Each section has 10 monitoring stations of eccentric load coefficient of normal stress D1 D10, and 3 monitoring stations of eccentric load coefficient of shear stress D11, D12, D13. This paper takes two loading conditions to study eccentric load coefficient of partial cable-stayed bridge with corrugated steel webs, as shown in Figure 7, loading symmetrical P / 2 (two) and eccentric load at

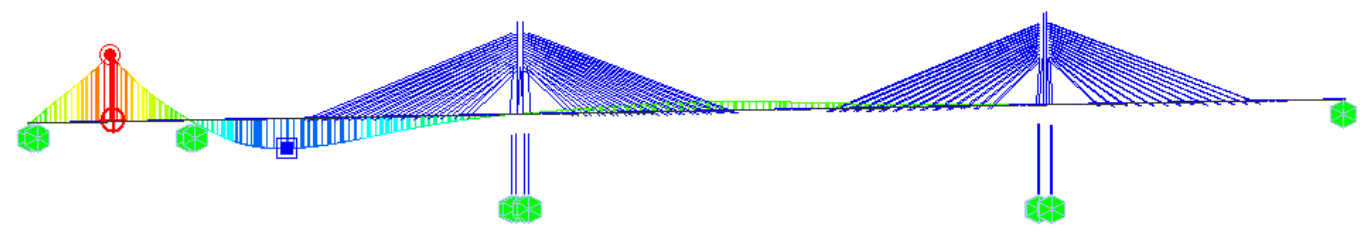

(a)

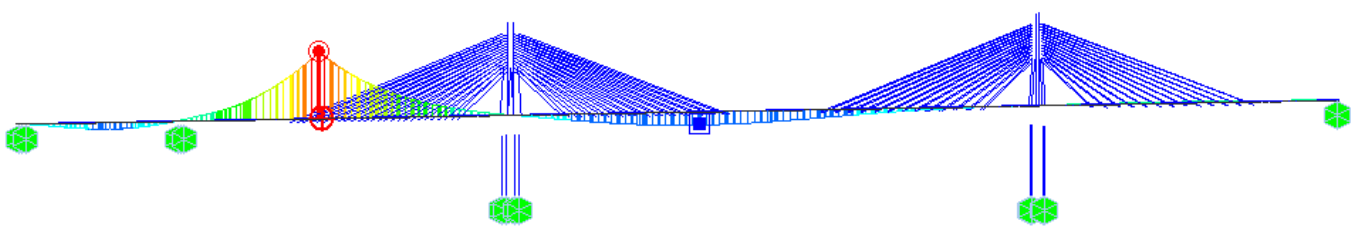

(b)

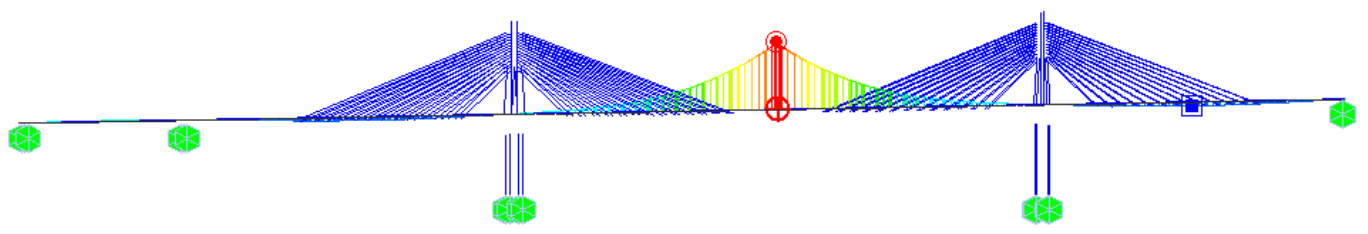

(c)

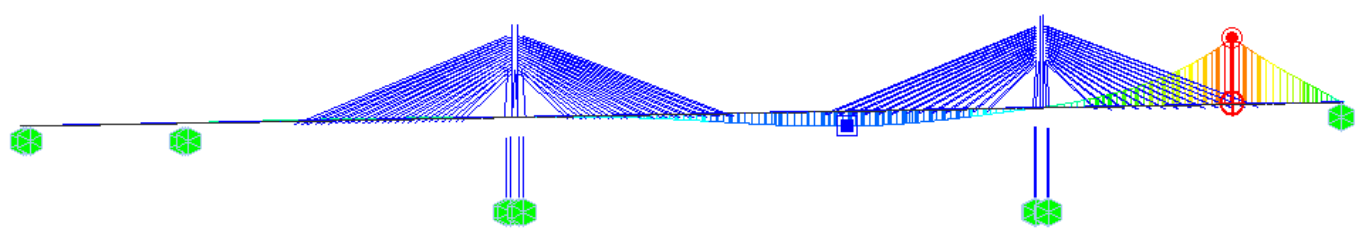

(d)

Figure 4 Internal force influence lines of cross sections

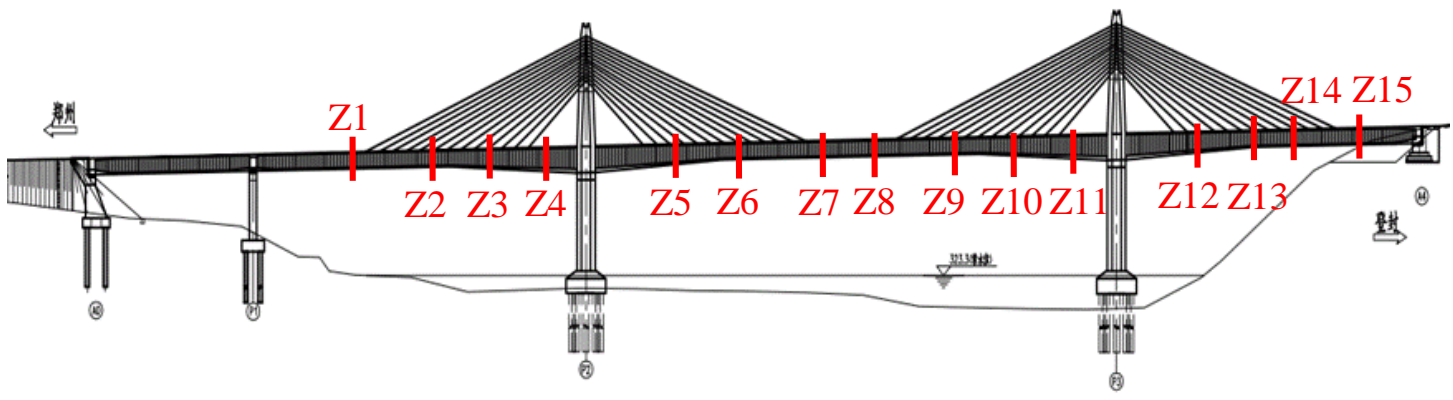

Figure 5 Location of main control sections Z1 Z15 


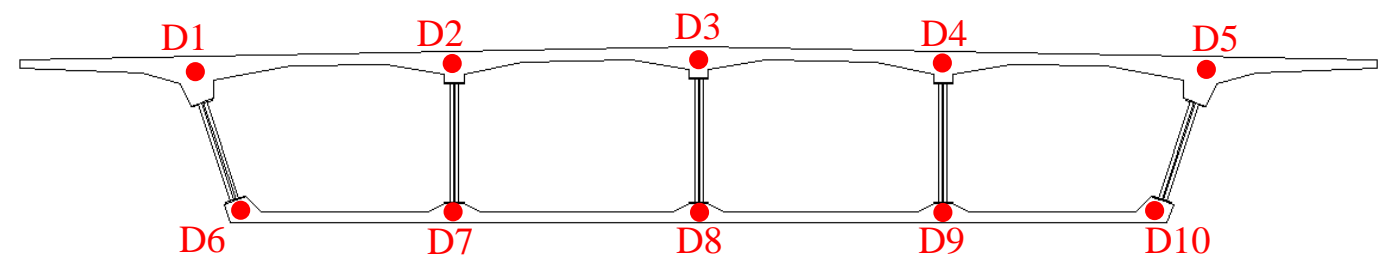

Figure 6 Monitoring stations on the control section

the across. $\mathrm{P}$ is $800 \mathrm{kN}$, the summation of the weight of 2040 -ton double-axle trucks. The load position along the longitudinal direction is $118 \mathrm{~m}$ the second across the span, $188 \mathrm{~m}$ the third across, and the forth across.

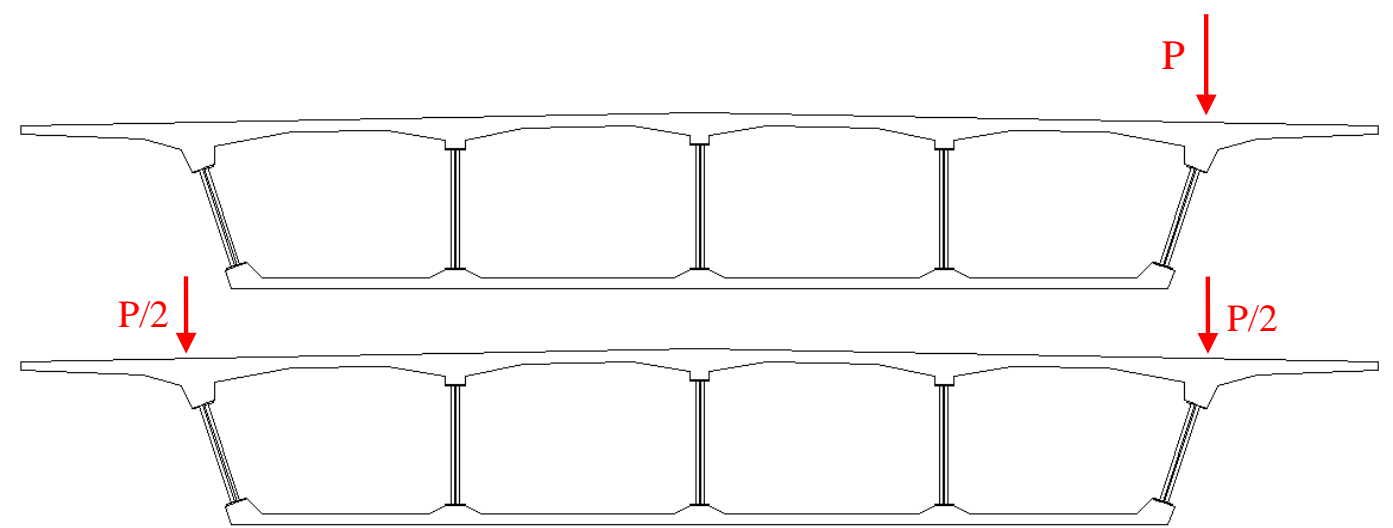

Figure 7 symmetrical and eccentric load

Calculations of 188m the third across section Z8 (Figure 7) are listed in Table 1. From the table, the eccentric load coefficient of normal stress of section $\mathrm{Z8}$ is 1.38 , and the maximum value of monitoring points appears in D10, namely the intersect angle point between the abdominal board on the eccentric load side and floor. The calculation results are reasonable and consistent with related researches. The eccentric load coefficient of shear stress of section Z8 is 1.68, larger than the empirical eccentric load coefficient of shear stress under live load. It means that the corrugated steel webs have great effect on the empirical eccentric load coefficient of shear stress. The maximum value of monitoring points appears in D13, namely the midpoint of the abdominal board on the eccentric load side. The calculation results are reasonable and consistent with related researches. Compared with the section Z5, Z6, Z7, section Z8 is closer to the cross, and the effect of eccentric load on the cable-stayed bridge with low pylon is heavier. Therefore, it is necessary to appropriately enlarge cross-loaded coefficients in design to enhance the stability of the bridge.

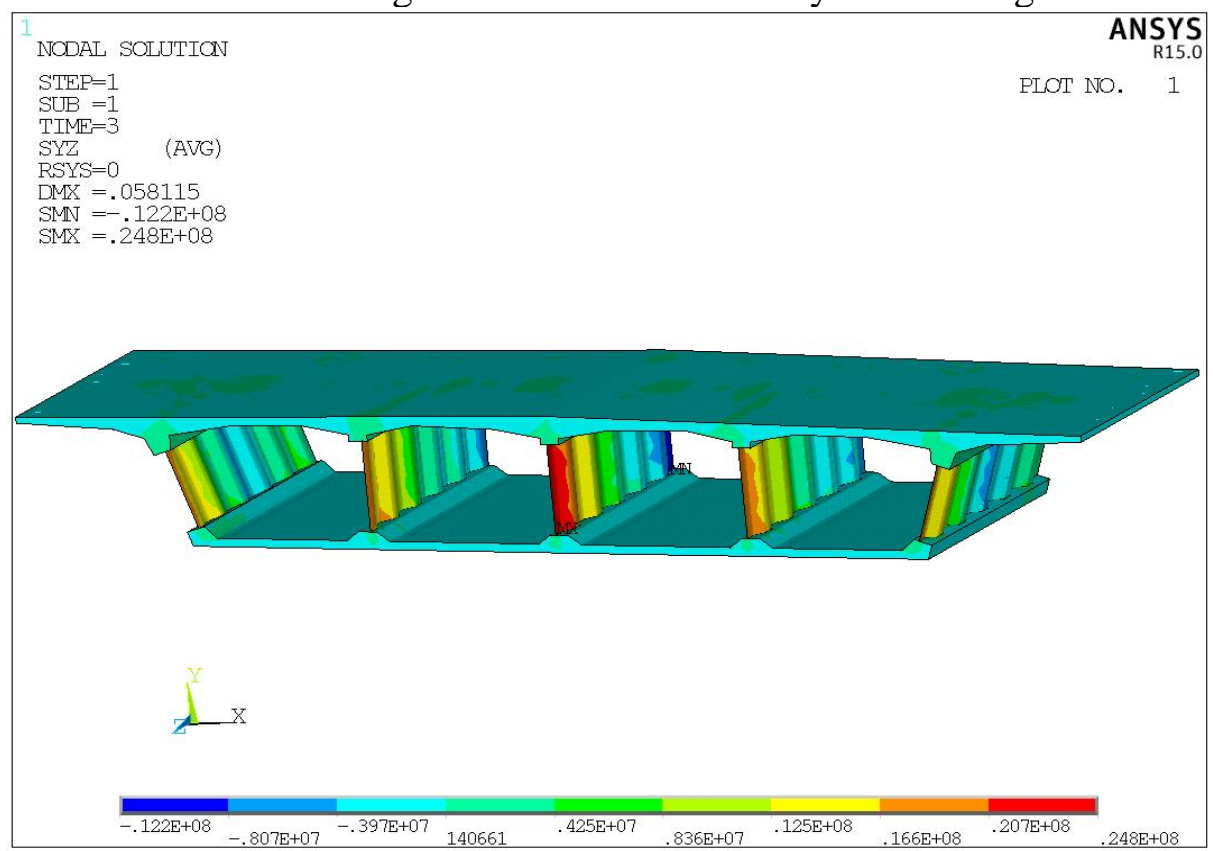

Figure 8 Shear stress in section Z8 
Table 1 Normal stress and shear stress in section Z8

\begin{tabular}{ccccc}
\hline \multirow{2}{*}{ Monitoring point } & \multicolumn{4}{c}{ Section Z8 } \\
\cline { 2 - 5 } & \multicolumn{4}{c}{ Normal stress/Pa } \\
\cline { 2 - 5 } & Bridge load & Symmetrical load & Eccentric load & Eccentric load coefficient \\
\hline D1 & -7131910.63 & -7228572.66 & -7194892.8 & 0.651570943 \\
D2 & -8414116.84 & -8501797.79 & -8489797.9 & 0.863141424 \\
D3 & -8691659.34 & -8773720.03 & -8786114.01 & 1.151034314 \\
D4 & -7824882.79 & -7907696.89 & -7931652.17 & 1.289265717 \\
D5 & -6113452.52 & -6212316.51 & -6269212.92 & 1.575501859 \\
D6 & -15338789.2 & -15103654.7 & -15253892.8 & 0.361054631 \\
D7 & -15177198.2 & -15023990.2 & -15065590.7 & 0.728470445 \\
D8 & -15109877.1 & -14980417.1 & -14963596.1 & 1.129932025 \\
D9 & -14863775.1 & -14710569.1 & -14669265.76 & 1.269593474 \\
D10 & -14599135.5 & -14380484.8 & -14295942.32 & 1.386655417 \\
\hline
\end{tabular}

Analysis results of all test sections Z1 Z15, and get the distribution of eccentric load coefficient of normal stress of the cable-stayed bridge with low pylon along the longitudinal direction (Table 2 and Figure 9). Figure 9 shows that the normal stress changes along the span of

Table 2 Distribution of eccentric load coefficient of normal stress and shear stress of the cable-stayed bridge with low pylon along the longitudinal direction

\begin{tabular}{|c|c|c|}
\hline \multirow{2}{*}{ Section } & \multicolumn{2}{|c|}{ Eccentric load coefficient } \\
\cline { 2 - 3 } & Normal stress & Shear Stress \\
\hline Z1 & 1.18 & 1.68 \\
\hline Z2 & 1.09 & 1.59 \\
\hline Z3 & 1.25 & 1.73 \\
\hline Z4 & 1.29 & 1.69 \\
\hline P2 Pier & - & - \\
\hline Z5 & 1.25 & 1.54 \\
\hline Z6 & 1.32 & 1.42 \\
\hline Z7 & 1.35 & 1.49 \\
\hline Z8 & 1.38 & 1.68 \\
\hline Z9 & 1.34 & 1.63 \\
\hline Z10 & 1.33 & 1.64 \\
\hline Z11 & 1.25 & 1.59 \\
\hline P3 Pier & - & - \\
\hline Z12 & 1.18 & 1.57 \\
\hline Z13 & 1.13 & 1.55 \\
\hline Z14 & 1.27 & 1.68 \\
\hline Z15 & 1.24 & 1.52 \\
\hline
\end{tabular}




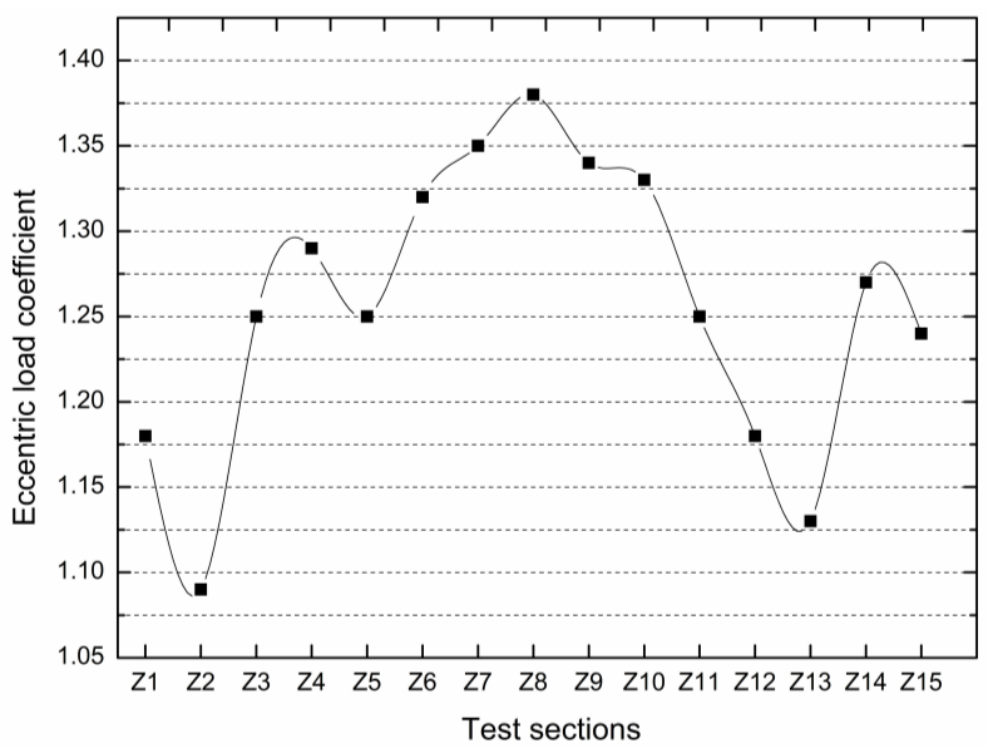

Figure 9 Distribution of eccentric load coefficient of normal stress and shear stress along the longitudinal direction

the bridge, the effect of eccentric load on normal stress is more obvious. The average of eccentric load coefficient of normal stress is 1.25 .

\section{Conclusion}

(1) Eccentric load coefficient of normal stress and shear stress of the cable-stayed bridge with low pylon with corrugated steel webs is not a constant along the longitudinal direction. Different sections have different coefficients, the largest in the across and decreasing on both sides.

(2) Eccentric load coefficient of normal stress and shear stress of the cable-stayed bridge with low pylon with corrugated steel webs changes obviously in the mutation between the uniform section and non-uniform section, characterized by that the eccentric effect is significant in the location of the high beam.

(3) The calculation results are reasonable and consistent with related researches. The normal stress changes along the span of the bridge, and the effect of eccentric load on normal stress is more obvious. It is necessary to appropriately enlarge cross-loaded coefficients in design to enhance the stability of the bridge. The distribution of eccentric load coefficient from the analysis can be used in some situation and can be a reference for the design and analysis of continuous girder bridge with variable cross-section.

\section{References}

[1] Liu Haiyan. List of PC box-girder with corrugated steel webs built in Japan [J].2002,30(1):58 59.

[2] Li Hongjiang. Experimental Study and Analysis on Torsion and Distortion of Box-girder with Corrugated Steel Webs [D]. Southeast University.2003.

[3] Ma Lei. Study on Bending and Torsion of Single Box Multi-cell Girder with Corrugated Steel Webs [D]. Southeast University.2015.

[4] Guo Jinqiong. Box Beam Design Theory [M]. Beijing. China Communications Press. 1991.

[5] Liu Zhao. Theory of Conceptual Design and Analysis of Bridges [M]. Beijing. China Communications Press. 2010.

[6] Guo Yi, Ye Jianshu, Wan Hongyan. Study on Load Test of Pre-stressed Concrete Box Girder [J]. Journal of Heilongjiang Institute of Technology, 2002(04):14-16.

[7] C. C. Fu, Yao T Hsu. Bridge Diaphragm Elements with Partial Warping Restraint[J]. Journal of structural engineering, 1994120(11). 